\title{
Incidence of Inguinal Herniotomy in Children. A Prospective Study at a Regional Hospital.
}

\section{Devendra Shrestha ${ }^{1}$, Narendra Vikram Gurung ${ }^{2}$, Suresh Raj Poudel ${ }^{3}$, Santosh Shrestha ${ }^{4}$, Dilip Baral $^{5}$, Sushil Timilsina ${ }^{6}$}

Department of Surgery, Pokhara Academy of Health Sciences, Western Regional Hospital, Pokhara

\section{Correspondence}

Dr. Devendra Shrestha

Department of Surgery, Pokhara Academy of Health Sciences, Western Regional Hospital, Pokhara.

Email: dsth10@yahoo.com

Article received: July 272020

Article accepted: Oct 22020

\section{ABSTRACT}

Background: Inguinal hernia is one of the most common surgical conditions in children. Herniotomy is the surgery performed for a pediatric hernia and hydrocele. This study was done to know the demography and outcome of pediatric herniotomy at our center.

Materials and methods: A prospective study on patients who underwent herniotomy from $10^{\text {th }}$ May 2016 to $9^{\text {th }}$ May 2017 was conducted at the Department of Surgery, Western Regional Hospital.

Results: During this study 112 patients underwent herniotomy out of which 98 were boys while 14 were girls. 59(52.67\%) patients had unilateral hernia, 40(35.71\%) had unilateral hydrocele and $13(11.6 \%)$ had bilateral condition among which 8 had hernia and 5 had hydrocele. $69(61.6 \%)$ patients presented with a right-sided, 30(26.7\%) with leftsided, and $13(11.6 \%)$ with bilateral conditions. 13 patients $(11.6 \%)$ presented at the emergency with irreducible hernia. Two among the patient who underwent emergency herniotomy developed postoperative wound infection and one among the elective surgery had recurrence.

Conclusion: Pediatric inguinal hernias and hydroceles are often difficult to diagnose clinically. Herniotomy is often performed by junior consultants who have no specific training in pediatric surgery. Timely planning of surgery is required to minimize preoperative complications.

Keywords: Inguinal hernia, hydrocele, herniotomy.

rate of inguinal hernia for full-term and premature neonates have reported to be $1-5 \%$ and $9-11 \%$ respectively ${ }^{3,4,5}$ and it is six times more common in boys. ${ }^{6,78}$ Inguinal hernia repair or herniotomy is considered as the most common elective surgical procedure in children with inguinal hernia. ${ }^{2}$ The procedure can be difficult even in the most experienced hands and especially when performed as an emergency. ${ }^{9}$ It is usually performed by junior surgeons or consultants without specific pediatric surgery training, so we conducted prospective study same spatial remnan ${ }^{2}$. The surgical correctio 0 both pathologies is similar. The estimated prevalence 
Original Article

to find out the demography and outcome of surgery (herniotomy) in the Department of Surgery, Western Regional Hospital in one year.

\section{MATERIALS AND METHODS}

All the children up to the age of 14 years, who underwent herniotomy within 1 year $\left(10^{\text {th }}\right.$ May 2016 to $9^{\text {th }}$ May 2017) were included. Most of the patients with inguinal hernia were diagnosed clinically alone and ultrasound was used infrequently as a diagnostic tool in clinically doubtful cases. These patients were followed up for 2 years. All patients, operated electively, were admitted one day prior and operated under intravenous anesthesia. Those patients who were operated electively, oral feeding started after 3 hours of surgery and discharged the next day only. Those who underwent emergency herniotomy, feeding was started on $1^{\text {st }}$ postoperative day and discharged on 2nd postoperative day. Most of the patients were followed on the $7^{\text {th }}$ postoperative day and as needed. All the patients were advised to do follow up every 6 months for 2 years. Patients not having even a single follow-up up to the end of 2 years were excluded from the study. Patients data was collected in preformed performa and entered in SPSS version 20 and analysed. Categorical variables are reported in frequency and percentage and a $\mathrm{P}$ value of $<0.05$ is considered significant.

\section{RESULTS}

During this study, 112 patients underwent herniotomy. Out of these patients, 98 were boys and 14 were girls $(p=0.001)$. The commonest age of presentation was below 5 years which was total 54 $(48.21 \%)$, the youngest baby being 1 months old. Mean age of the patient with hernia was $5.58 \pm 4.30$ years while that of patients with hydrocele was $6.73 \pm 4.49$ years months, on comparison it was found to be statistically insignificant $(\mathrm{p}>0.05)$. Among total patients, 59(52.67\%) patients had unilateral hernia and $40(35.71 \%)$ had unilateral hydrocele. $13(11.6 \%)$ had bilateral, among which 8 were with hernia, and 5 were with hydrocele. One patient had right-sided recurrent hernia which was previously operated at other center. All the hernias were indirect. In those who had bilateral condition, surgery on the other side was performed after 3 months. $69(61.6 \%)$ patients had on the right side, $30(26.7 \%)$ had on left side and 13(11.6\%) with bilateral conditions. 13 patients $(11.6 \%)$ presented at emergency with irreducible hernia (12 male and 1 female), 9 were below 12 months. All these patients were operated on the same day of admission, 3 had enterocele and 10 had omentocele. None of
Medical Journal of Pokhara Academy of Health Sciences Vol. 3 Issue 2

the children needed resection of sac contents. One patient had sliding hernia with sac containing caecum. 2(1.8\%) among the patient who underwent emergency herniotomy developed postoperative wound infection and $1(0.9 \%)$ among the elective surgery had recurrence.

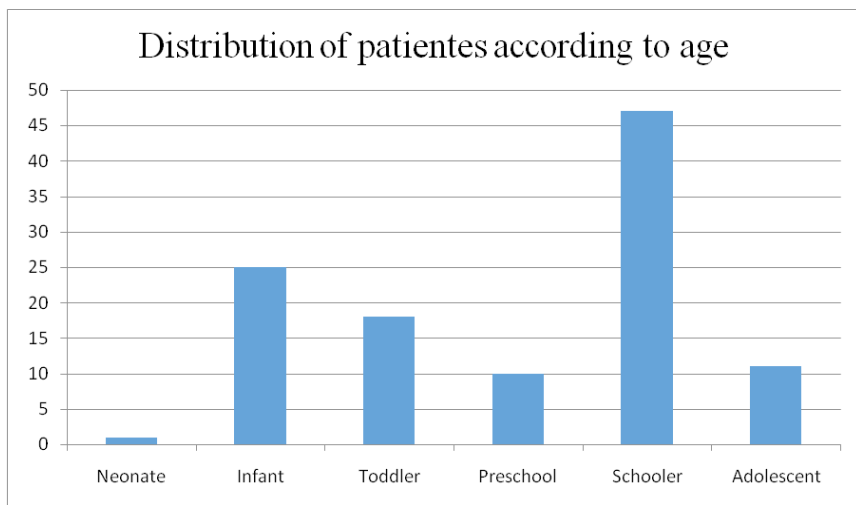

Figure no. 1

No. of Patients according to side

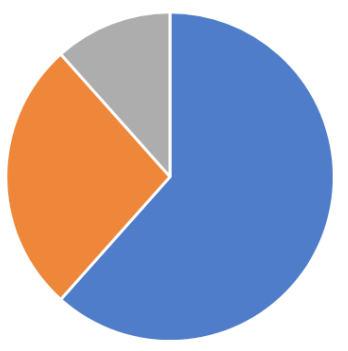

- Right Sided - Left Sided $\quad$ - Bilatral

\section{Figure no.2}

\section{DISCUSSION}

Inguinal hernia and hydrocele, one of the most common conditions encountered during pediatric surgery practice. Most often, the hernia are asymptomatic, which are detected during the first few years of life and at birth in premature babies. In this study, the commonest age of presentation was below 5 years which was total 54 (48.21\%), the youngest baby being 1 months old. In the study series of Yih-Hung Chen et al.$^{10}$ the male to female ratio was 8.94:1 which is almost similar in our study $(8.75: 1.25)$.

The estimated prevalence rate of inguinal hernia for full-term and premature neonates have reported to be $1-5 \%$ and $9-11 \%$ respectively. ${ }^{3,4,5}$ Incidence of inguinal hernia in our study on right, left and both 
sides is quite similar to other studies done by Rowe et al. and Grosfeld. ${ }^{11}$

13 patients were admitted in emergency basis with irreducible hernias, that is $11.86 \%$ which contained small bowel in 3 childern and omentum in 9 children. Resection of sac contents was not required in any case. 9 patients were below 12 months of age. A similar rate of irreducible hernia in infants under one year of age has been noted by others and emphasizes the need for elective operative treatment of inguinal hernia as soon as is practical following diagnosis. Emergency operation for irreducible hernia can be a difficult procedure because the cord structures and hernial sac are often very edematous and the risk of damage to the delicate testicular vessels and vas deferens is much higher than in elective herniotomy. ${ }^{12}$

Routine hernia repairs are performed on a day care basis. In this study, most of the patients were treated as in-patients, with the average duration of the hospitalization being between 1-3 days. The reasons for this being the necessity of performing the investigations as in patients and the unavailability of adequate anesthetic and neonatal facilities in the postoperative period (most of our patients were from remote village areas).

A controversy exists for routine contra-lateral exploration in the absence of a clinical inguinal hernia. Various modalities have been described for detecting contra-lateral hernias, but their efficacy and necessity are debatable. Rescorla et al. ${ }^{13}$, recommended a routine exploration of the opposite site. The recent consensus is on a contra-lateral exploration, only when it is indicated. In this study, only the side with an obvious hernia was operated on. Direct inguinal hernias in children are rare and they represent $0.5 \%$ of all the groin hernias. Fonkalsrud et al., reported 13 patients with direct inguinal hernias amongst 5,452 operations for inguinal hernias which were done over 17 years while Wright J.E. reported 19 direct inguinal hernias in 14 patients among over 1,600 inguinal hernia operations $^{14}$. In the present study, direct hernia were not detected in all the inguinal hernias.

Sliding inguinal hernia are uncommon in children. The structures which are encountered in the sliding hernia are the caecum, appendix, bladder, sigmoid colon, and rarely, the uterus. In the present study, one child had a sliding inguinal hernia on the right side, which contained the caecum.

Regarding complications, 2 children from
Incidence of inguinal herniotomy in children. Shrestha D. et. al.

emergency group developed postoperative wound infection that was $1.8 \%$ of total patients. There was one recurrence in patient who underwent elective surgery which is $0.9 \%$ of the elective group. The incidence of late complications of herniotomy including testicular atrophy, high testes, and infertility due to damage to the vas deferens could not be commented due to short follow-up.

\section{CONCLUSION}

Inguinal hernia and hydrocele are common congenital conditions in children. General surgeons often face difficulties in identifying and confirming the presence of these conditions, herniotomy can be performed by junior surgeons or consultants with no specific pediatric surgery training in resource limited setting although the outcome will be better if done by specialist hernia surgeons. These should be operated as soon as possible in children due to the risk of having preoperative complications.

\section{REFERENCES}

1. Hutson JM, O'Brien M, Beasley SW, Teague WJ, King SK. Jones' clinical paediatric surgery. 7th edn. Chichester: John Wiley \& Sons, 2015. p. 332.

2. Clarke S. Pediatric inguinal hernia and hydrocele: an evidence-based review in the era of minimal access surgery. J Laparoendosc Adv Surg Tech A. 2010;20(3):305-9.

3. Nazem M, Heydari Dastgerdi MM, Sirousfard M. Outcomes of pediatric inguinal hernia repair with or without opening the external oblique muscle fascia. Vol. 20, Journal of Research in Medical Sciences. 2015. p. 1172-6.

4. Coran AG, Fonkalsrud EW, Grosfeld JL, O’Neill JA. 6th ed. Philadelphia: Mosby Elsevier; 2006. Pediatric Surgery.

5. Yeap E, Nataraja RM, Pacilli M. Inguinal hernias in children. Aust J Gen Pract. 2020;49(1-2):38-43.

6. Bowling K, Hart N, Cox P, Srinivas G. Management of paediatric hernia. BMJ. 2017;359:1-6.

7. Öberg S, Andresen K, Rosenberg J. Etiology of Inguinal Hernias: A Comprehensive Review. Front Surg. 2017;4(September):1-8.

8. Weaver KL, Poola AS, Gould JL, Sharp SW, St Peter SD, Holcomb GW 3rd. The risk of developing a symptomatic inguinal hernia in children with an asymptomatic patent processus 
vaginalis. J Pediatr Surg 2017;52(1):60-64.

9. Swenson 0. Inguinal hernia. In: Raffensperger JC. ed. Paediatric surgery 4th ed. New York: AppletonCentury-Croft; 1980:107-20.

10. Chen Y-H, Wei C-H, Wang K-WK. Children With Inguinal Hernia Repairs: Age and Gender Characteristics. Glob Pediatr Heal. 2018;5(46):2333794X1881690.

11. Singh H, Wagh DD. Original article Management of congenital inguinal hernia at A . V . B . R . H. 2016;5(4):13-23.

12. Pradhan GB, Shrestha D, Shrestha S, Bhattachan CL. Inguinal herniotomy in children : a one year survey at Nepal Medical. Nepal Med Coll J. 2011;13(4):301-2.

13. Rescorla FJ, Grosfeld JL. Inguinal hernia repair in the perinatal period and early infancy: Clinical considerations. J Pediatr Surg. 1984;19(6):832-7.

14. Ravikumar V, Rajshankar S, Hareesh RSK,Nagendra GMR. A Clinical Study on the Management of Inguinal Hernias in Children on the General Surgical Practice. J Clin Diagn Res. 2013 Jan; 7(1): 144-147. 